\title{
Abolishing inequity, a necessity for poverty reduction and the realisation of child mortality targets
}

\author{
Mats Målqvist
}

\section{Correspondence to}

Dr Mats Målqvist, Department of Women's and Children's Health, International Maternal and Child Health, Uppsala University, Uppsala 75185, Sweden;

mats.malqvist@kbh.uu.se

Received 2 July 2014

Revised 28 July 2014

Accepted 31 July 2014
CrossMark

To cite: Målqvist M. Arch Dis Child 2015;100

(Suppl 1):s5-s9.

\section{ABSTRACT}

The first Millennium Development Goal (MDG 1) due in 2015 concerns poverty reduction. It has been claimed to be fulfilled on a global level, but still more than 1 billion people are living in abject poverty. There is a strong link between the economy and child survival, and only a minority of countries will have reached the MDG target for child mortality reduction by 2015 . This paper discusses the relationship between poverty and child survival. It argues that a focus on equity is necessary to further reduce child mortality, through poverty reduction in absolute terms and also through targeting

interventions for increased child survival to disadvantaged populations. The political will to actually achieve real change for those in greatest need is crucial but not to be taken for granted, and the distribution rather than the generation of wealth needs to be made a priority in the post-MDG era.

\section{INTRODUCTION}

The first Millennium Development Goal (MDG 1) deals with the allocation of resources and halving the rate of extreme poverty and hunger by 2015 compared to the level in $1990 .^{1}$ It has been claimed that this goal was fulfilled some years ago. ${ }^{12}$ The proportion of extremely poor people living on less than US\$1.25 a day has decreased, but the population has grown and today more than 1 billion people still live in abject poverty. ${ }^{1}{ }^{2}$ Furthermore, the global success in reaching the first MDG can to a large extent be attributed to the tremendous economic development in East Asia over the past two decades (tables $1-4) .^{3}$ China alone has made a major contribution to the achievement of MDG 1. However, not much has happened in Africa. In countries like Kenya, Nigeria and Zambia, the ratio of people living on less than US $\$ 1.25$ a day has actually increased (table 4). ${ }^{2}{ }^{3}$ This raises the question whether achieving MDG 1 was due to the MDG effort or was just the result of inevitable development as the most populous country on Earth reached a developmental tipping point. This suggestion has both positive and negative implications-positive in the sense that once the economy of a developing society reaches a critical mass the rate of poverty will decrease as a result, and negative in the sense that world community efforts may ultimately be irrelevant as macroeconomics have a dynamic of their own. However, people drive development and changes can be made, for example, in child mortality. The so-called 'child survival revolution' from the 1970 s to the turn of the millennium, when under-5 mortality fell substantially worldwide, ${ }^{4}$ testifies to the possibility of achieving change with determination and effort unrelated to economic development. For example, before it experienced the tremendous economic development of later years, Vietnam managed to reduce child mortality from 55/1000 to $30 / 1000$ live births through community mobilisation and a deliberate effort to improve public health through large-scale programmes for immunisation and health awareness. ${ }^{5}$ The effort in the last 10 years to reduce neonatal mortality globally is another example how directed effort can make a difference. ${ }^{4}$ However, despite significant improvements in under-5 mortality, neonatal mortality remains high. Efforts such as Countdown to 2015 and Saving Lives at Birth have contributed to the focus on reducing neonatal deaths as a way to reach MDG 4. Even if not enough has been done to reach MDG 4 by 2015, the rate of reduction in neonatal mortality increased after 2005 despite the 2008 global economic downturn. ${ }^{6}$ One example of a positive development is found in Nepal, where a priority for the last 15 years has been to reduce neonatal mortality. From being a neglected issue, awareness of neonatal mortality was increased and it was reduced from 50 to $33 / 1000$ over 10 years. $^{7}$ The political will, financial back-up and national attention given to neonatal health have been suggested as key factors in this success. ${ }^{8}$

\section{ECONOMIC DEVELOPMENT AS A DRIVER FOR CHILD SURVIVAL}

Despite the above-mentioned examples, it is abundantly clear that economic development promotes health, including child health and survival. There is a strong correlation between a country's economic strength and newborn, infant and child death rates (figure 1). This is because of the extra resources available and the overall organisational efficiency and service delivery which come with economic growth. ${ }^{2}$ The aggravating effects of poverty on child health, ranging from preconception malnutrition of mothers to financial obstacles to inadequate healthcare seeking and receiving for children, also implies a great potential for improvement through small changes in economic power among the poorest. ${ }^{9}$ Community based interventions and peer support models indicate that large improvements can be made with small investments. ${ }^{10-12}$ Analyses of the cost-effectiveness of interventions for neonatal survival show that the disability-adjusted life years (DALYs) avoided cost little, making it more likely that these interventions can be applied in countries struggling with limited resources. ${ }^{13}$ Of 
Table 1 Countries that have achieved both Millennium Development Goal 1 (MDG 1) and MDG 4

\begin{tabular}{|c|c|c|c|c|c|c|c|c|}
\hline \multirow[b]{2}{*}{ Country } & \multicolumn{3}{|c|}{ Poverty ratio at $\$ 1.25$ a day (\% of population) } & \multicolumn{5}{|c|}{ Under-5 mortality rate (per 1000 live births) } \\
\hline & Year 1 & Year 2 & Target met & 1990 & 2012 & MDG 4.1 target & Reduction in U5MR (\%) & Target met \\
\hline Armenia & $17.5(2006)$ & $2.5(2010)$ & Yes & 49.4 & 16.4 & 16.3 & 67 & Yes \\
\hline Brazil & $17.2(1990)$ & $6.1(2009)$ & Yes & 61.7 & 14.4 & 20.4 & 77 & Yes \\
\hline China & $60.2(1990)$ & $11.8(2009)$ & Yes & 54.0 & 14.0 & 17.8 & 74 & Yes \\
\hline Egypt & 4.5 (1991) & 1.7 (2008) & Yes & 85.5 & 21.0 & 28.2 & 75 & Yes \\
\hline Iran & 3.9 (1990) & 1.5 (2005) & Yes & 56.4 & 17.6 & 18.6 & 69 & Yes \\
\hline Nepal & 68.0 (1996) & $24.8(2010)$ & Yes & 141.9 & 41.6 & 46.8 & 71 & Yes \\
\hline Peru & 12.9 (1994) & $4.9(2010)$ & Yes & 79.1 & 18.2 & 26.1 & 77 & Yes \\
\hline Tunisia & $5.9(1990)$ & $1.1(2010)$ & Yes & 51.2 & 16.1 & 16.9 & 69 & Yes \\
\hline Uruguay & 0.9 (1992) & $0.2(2010)$ & Yes & 23.1 & 7.2 & 7.6 & 69 & Yes \\
\hline
\end{tabular}

Source: World Bank, http://data.worldbank.org/ (accessed 7 Jun 2014).

U5MR, under-5 mortality rate.

course, much political will is also required, but since inadequate interventions and healthcare delivery are just part of the problem, reducing poverty will considerably increase the chances of child survival.

\section{CHILD SURVIVAL AS A DRIVER FOR ECONOMIC DEVELOPMENT}

However, it can be argued that economic growth cannot happen without the necessary socioeconomic improvements: the economic tipping point, or critical mass, cannot be reached unless the struggle for everyday survival does not consume all energy and make investments a pointless and non-affordable luxury. A certain level of food security and basic health interventions to overcome the worst health hazards, together with favourable political circumstances, are needed before a country can gain industrial and economic momentum. ${ }^{14}$ Since children are both a considerable investment and a necessity for economic security, the chances of children surviving affect the number of children in each household. ${ }^{14}$ The possibility that children will die early makes long-term planning futile and creates a vicious circle of too many mouths to feed to have any surplus for investments. With improved child survival, investments in education and the health of the family become more secure and the number of family members can be reduced, thus increasing the share of available resources for each person. This development is reflected both in the dramatic voluntary drop in fertility rates in South East Asia as well as in the increased age of European primipara women. ${ }^{15} 16$ When child deaths become rare, life investments can be directed towards economic development.

\section{EQUITY IS KEY}

A central aspect of MDG 1 is equity, the justifiable allocation and division of resources. Although there is no shortage of food in the world, more than a billion people do not have enough to eat on a daily basis. ${ }^{2}$ It has recently also been acknowledged more fully in the economic discourse that the prevailing belief that riches will 'trickle down' does not hold true. ${ }^{17}$ Instead, the wealth of the world is becoming more and more concentrated in the hands of the few. ${ }^{17}$ This is true in the rich and poor areas of the world-the so-called 'resource curse' or the 'paradox of plenty' is illustrated by the two outliers in figure 1, Equatorial Guinea and Angola. ${ }^{18}$ Both countries have recently discovered large oil reserves, but the rapidly increasing gross domestic product (GDP) has not benefitted the entire population. This means that the struggle to reduce poverty needs to move the focus away from growth generation to growth distribution.

The poverty gap is an indicator that shows the percentage of the population below the poverty line, and also illustrates how

Table 2 Countries that have achieved Millennium Development Goal 1 (MDG 1) but not MDG 4

\begin{tabular}{|c|c|c|c|c|c|c|c|c|}
\hline \multirow[b]{2}{*}{ Country } & \multicolumn{3}{|c|}{ Poverty ratio at $\$ 1.25$ a day (\% of population) } & \multicolumn{5}{|c|}{ Under-5 mortality rate (per 1000 live births) } \\
\hline & Year 1 & Year 2 & Target met & 1990 & 2012 & MDG 4.1 target & Reduction in U5MR (\%) & Target met \\
\hline Azerbaijan & $16.3(1995)$ & $0.4(2008)$ & Yes & 92.8 & 35.2 & 30.6 & 62 & No \\
\hline Cambodia & $44.5(1995)$ & $18.6(2009)$ & Yes & 116.4 & 39.7 & 38.4 & 66 & No \\
\hline Ecuador & $14.1(1994)$ & $4.6(2010)$ & Yes & 55.8 & 23.3 & 18.4 & 58 & No \\
\hline Guatemala & $39.1(1989)$ & $13.5(2006)$ & Yes & 80.4 & 32.0 & 26.5 & 60 & No \\
\hline Honduras & $46.9(1990)$ & 17.9 (2009) & Yes & 58.9 & 22.9 & 19.4 & 61 & No \\
\hline Indonesia & $54.3(1990)$ & 16.2 (2011) & Yes & 83.8 & 31.0 & 27.7 & 63 & No \\
\hline Malaysia & 1.6 (1992) & 0.0 (2009) & Yes & 16.6 & 8.5 & 5.5 & 49 & No \\
\hline Mexico & 4.8 (1992) & 0.7 (2010) & Yes & 46.2 & 16.2 & 15.3 & 65 & No \\
\hline Pakistan & 64.7 (1991) & $21.0(2008)$ & Yes & 138.4 & 85.9 & 45.7 & 38 & No \\
\hline Senegal & 65.8 (1991) & $29.6(2011)$ & Yes & 142.0 & 59.6 & 46.9 & 58 & No \\
\hline Thailand & $11.6(1990)$ & $0.4(2010)$ & Yes & 38.2 & 13.2 & 12.6 & 65 & No \\
\hline Vietnam & 63.7 (1993) & 16.9 (2008) & Yes & 50.5 & 23.0 & 16.7 & 54 & No \\
\hline
\end{tabular}

Source: World Bank, http://data.worldbank.org/ (accessed 6 Jul 2014).

U5MR, under-5 mortality rate. 
Table 3 Countries that have achieved Millennium Development Goal 4 (MDG 4) but not MDG 1

\begin{tabular}{|c|c|c|c|c|c|c|c|c|}
\hline \multirow[b]{2}{*}{ Country } & \multicolumn{3}{|c|}{ Poverty ratio at $\$ 1.25$ a day (\% of population) } & \multicolumn{5}{|c|}{ Under-5 mortality rate (per 1000 live births) } \\
\hline & Year 1 & Year 2 & Target met & 1990 & 2012 & MDG 4.1 target & Reduction in U5MR (\%) & Target met \\
\hline Bangladesh & $70.2(1992)$ & $43.3(2010)$ & No & 143.6 & 40.9 & 47.4 & 72 & Yes \\
\hline Ethiopia & $60.5(1996)$ & $30.7(2011)$ & No & 204.0 & 68.3 & 67.3 & 67 & Yes \\
\hline Malawi & $83.1(1998)$ & $61.6(2010)$ & No & 243.7 & 71.0 & 80.4 & 71 & Yes \\
\hline Tanzania & 72.6 (1992) & 67.9 (2007) & No & 166.2 & 54.0 & 54.9 & 68 & Yes \\
\hline
\end{tabular}

Source: World Bank, http://data.worldbank.org/ (accessed 6 Jul 2014).

U5MR, under-5 mortality rate.

far below that line the poor are, thus giving a more complete picture. As shown in figure 2, there is a direct correlation between GDP and child mortality, and also between a country's level of poverty, as expressed by the poverty gap, and child mortality (figure 2). Thus, promoting equity becomes important for MDG 1 and for the health-related MDGs, ${ }^{19}$ for example in the small kingdom of Swaziland, where it is estimated $40-60 \%$ of the population live below the poverty line, despite the kingdom's GDP placing it among middle-income countries (table 4). As the child mortality rate in Swaziland is actually increasing, mostly due to unsuccessful attempts to prevent mother-to-child transmission of HIV, it is clear that uneven distribution of wealth results in human suffering.
As explained by the UN initiated Commission on Social Determinants of Health (CSDH), social position is an important social determinant of health. ${ }^{20}$ Where an individual is placed on the social ladder determines to a large extent his or her health status, thus creating inequity. This social position is in itself not bad and indeed is necessary for the creation of ambition and societal development, as has been shown by the many failed attempts to create utopian and egalitarian societies. But it is of concern when low social position imposes unjust disadvantages resulting in poorer health and lives lost. The promotion of equity in health, with maternal and child health as the ultimate litmus test as women and children generally have a lower social position than men, does not necessarily seek to eradicate

Table 4 Countries that have not achieved Millennium Development Goal 1 (MDG 1) or MDG 4

\begin{tabular}{|c|c|c|c|c|c|c|c|c|}
\hline \multirow[b]{2}{*}{ Country } & \multicolumn{3}{|c|}{$\begin{array}{l}\text { Poverty ratio at } \$ 1.25 \text { a day ( } \% \text { of } \\
\text { population) }\end{array}$} & \multicolumn{5}{|c|}{ Under-5 mortality rate (per 1000 live births) } \\
\hline & Year 1 & Year 2 & Target met & 1990 & 2012 & MDG 4.1 target & Reduction in U5MR (\%) & Target met \\
\hline Angola & $54.3(2000)$ & $43.4(2009)$ & No & 212.8 & 163.5 & 70.2 & 23 & No \\
\hline Argentina & $0.6(1990)$ & $0.9(2010)$ & No & 27.5 & 14.2 & 9.1 & 48 & No \\
\hline Bolivia & 5.2 (1991) & $15.6(2008)$ & No & 123.4 & 41.4 & 40.7 & 66 & No \\
\hline Cameroon & $10.8(2001)$ & $9.6(2007)$ & No & 134.9 & 94.9 & 44.5 & 30 & No \\
\hline Colombia & 8.2 (1991) & $8.2(2010)$ & No & 35.1 & 17.6 & 11.6 & 50 & No \\
\hline Cote d'Ivoire & 17.8 (1993) & $23.8(2008)$ & No & 151.8 & 107.6 & 50.1 & 29 & No \\
\hline Ghana & 51.1 (1992) & $28.6(2006)$ & No & 128.1 & 72.0 & 42.3 & 44 & No \\
\hline India & 53.6 (1988) & 32.7 (2010) & No & 125.6 & 56.3 & 41.5 & 55 & No \\
\hline Kenya & 38.4 (1992) & $43.4(2005)$ & No & 98.2 & 72.9 & 32.4 & 26 & No \\
\hline Lao PDR & 55.7 (1992) & 33.9 (2008) & No & 162.9 & 71.8 & 53.8 & 56 & No \\
\hline Lesotho & 56.4 (1993) & $43.4(2003)$ & No & 84.5 & 99.6 & 27.9 & -18 & No \\
\hline Madagascar & 72.5 (1993) & $81.3(2010)$ & No & 158.5 & 58.2 & 52.3 & 63 & No \\
\hline Mali & 86.1 (1996) & $50.4(2010)$ & No & 253.3 & 128.0 & 83.6 & 49 & No \\
\hline Mauritania & 42.8 (1993) & 23.4 (2008) & No & 127.8 & 84.0 & 42.2 & 34 & No \\
\hline Mozambique & 80.6 (1996) & 59.6 (2008) & No & 232.6 & 89.7 & 76.8 & 61 & No \\
\hline Namibia & 49.1 (1993) & 31.9 (2004) & No & 73.0 & 38.7 & 24.1 & 47 & No \\
\hline Nicaragua & $18.3(1993)$ & $11.9(2005)$ & No & 66.1 & 24.4 & 21.8 & 63 & No \\
\hline Nigeria & 61.9 (1992) & $68.0(2010)$ & No & 212.5 & 123.7 & 70.1 & 42 & No \\
\hline Paraguay & 11.5 (1995) & $7.2(2010)$ & No & 45.5 & 22.0 & 15.0 & 52 & No \\
\hline Philippines & 30.7 (1991) & 18.4 (2009) & No & 58.5 & 29.8 & 19.3 & 49 & No \\
\hline Rwanda & $74.6(2000)$ & $63.2(2011)$ & No & 150.9 & 55.0 & 49.8 & 64 & No \\
\hline Sierra Leone & $62.8(1990)$ & 51.7 (2011) & No & 257.3 & 181.6 & 84.9 & 29 & No \\
\hline South Africa & 24.3 (1993) & 13.8 (2009) & No & 60.8 & 44.6 & 20.1 & 27 & No \\
\hline Swaziland & 78.6 (1995) & 40.6 (2010) & No & 70.9 & 79.7 & 23.4 & -12 & No \\
\hline Uganda & 70.0 (1992) & 38.0 (2009) & No & 178.2 & 68.9 & 58.8 & 61 & No \\
\hline Venezuela & 4.4 (1992) & 6.6 (2006) & No & 29.5 & 15.3 & 9.7 & 48 & No \\
\hline Zambia & 61.1 (1991) & 74.5 (2010) & No & 191.9 & 88.5 & 63.3 & 54 & No \\
\hline
\end{tabular}

Source: World Bank, http://data.worldbank.org/ (accessed 6 Jul 2014).

U5MR, under-5 mortality rate. 


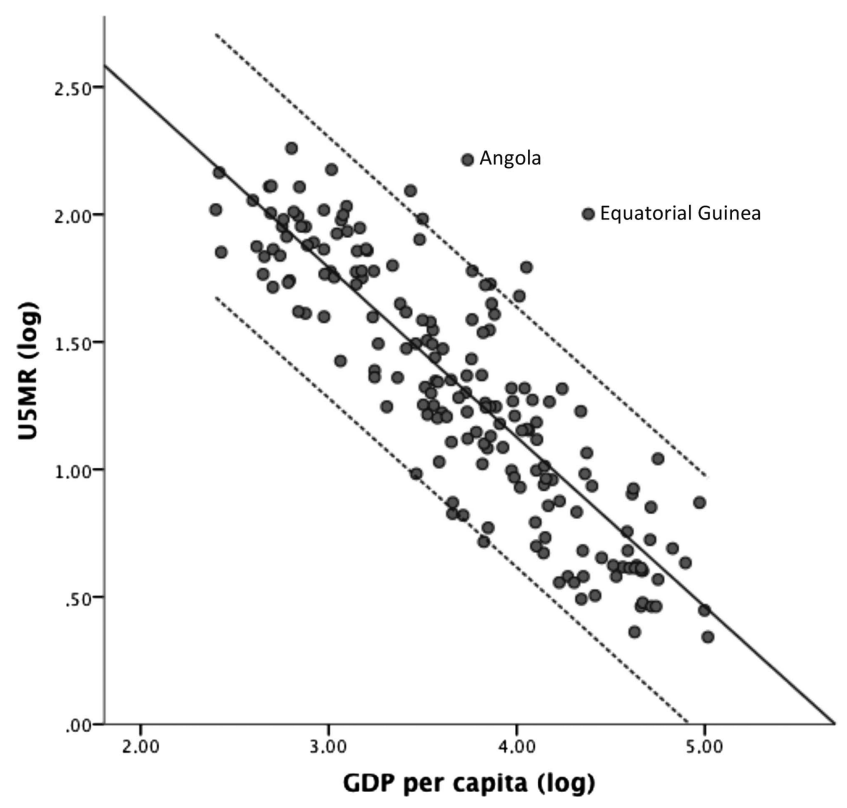

Figure 1 Under-5 mortality rate (U5MR) and gross domestic product per capita in 186 countries, 2012 (log-scale, line fit with 95\% Cls displayed). Source: World Bank, http://data.worldbank.org/ (accessed 6 Jul 2014).

economic inequalities. The adverse health effects of poverty per se are, however, unacceptable and thus the struggles for equitable health and poverty reduction share a common moral standpoint.

\section{INTERVENTIONS TARGETING THE POOR}

One way to combat both poverty and health inequity based on social position is to design health interventions that target the poor. ${ }^{21}$ Identifying and addressing the specific obstacles facing poor disadvantaged populations can produce gains in health while at the same time improving the chances of economic development. ${ }^{3}$ Different schemes to alleviate the burden of user fees in the health system, through conditional cash transfers, voucher systems or systems interventions, have been shown to

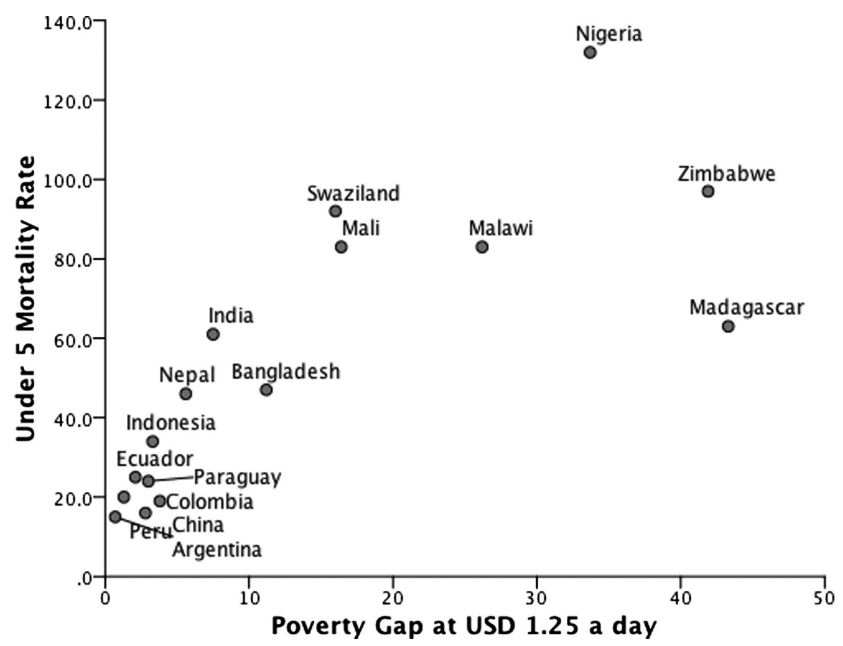

Figure 2 Under-5 mortality rate and poverty gap at US\$1.25 a day. The poverty gap is the mean shortfall from the poverty line expressed in percent of the poverty line (non-poor having zero percent). Source: World Bank, http://data.worldbank.org/ (accessed 6 Jul 2014). be effective in reducing child mortality and health inequity. ${ }^{21} 22$ Deliberate efforts to target poor populations at a national level can also contribute to economic growth. One such example comes from Bangladesh where the improvement in health has been disproportionately more beneficial for the poorer segments of society. ${ }^{23}$ Despite being one of the most challenging environments for development, Bangladesh has managed to hugely improve child survival by focusing on socioeconomic equity in other sectors in addition to health. Interventions such as the expansion of microfinance initiatives have also had beneficial effects for health outcomes. At the same time, large-scale investments in women-oriented interventions such as family planning programmes and female education subsidies have contributed to better child health. ${ }^{23}$ Similarly, a number of Latin America countries have introduced far-reaching interventions to address the barrier of user fees, thus contributing to socioeconomic development, ${ }^{24} 25$ an approach that has not been particularly evident in sub-Saharan Africa.

\section{CONCLUSION}

A focus on equity and a deeper analysis of child mortality is needed in order to avert the millions of unjustifiable child deaths worldwide. The strong link between poverty and child deaths strengthens this argument, and implies that reducing poverty and promoting a more equitable distribution of wealth are key for the successful continuation of the child survival revolution. It is true that the MDGs have given the research community, as well as NGOs and governments, a joint vision and common targets for their efforts. However, the success of these efforts varies, and it can be argued whether or not the first MDG has really been achieved, whether calculating in absolute or relative terms, or on a global or on a national level. ${ }^{3}$ In the same way it can be argued that global and national reductions in child mortality hide lack of development in disadvantaged minority populations. 'Cherry-picking' interventions to improve the situation a little for the majority rather than focussing on those who need help the most is an easy way around a moral obligation. Both for poverty reduction and improved child survival, in the end it all comes down to political will and leadership. Are decision-makers willing to pay the costs required and start prioritising health for the most disadvantaged rather than focusing on high military spending or bank bailouts? Likewise, it is time for the global community to step up to the real challenges of child survival and not hide behind diffuse and vague formulations like 'universal health coverage', but instead address the core issues of an unjust world.

\section{Competing interests None.}

Provenance and peer review Commissioned; internally peer reviewed.

\section{REFERENCES}

1 United Nations. Millennium Development Goals Report 2013. New York, 2013

2 Fan S. Public expenditures, growth, and poverty: lessons from developing countries. IFPRI Brief 51: International Food Policy Research Institute, 2008.

3 Clemens M, Kenny C, Moss T. The trouble with the MDGs: confronting expectations of aid and development success. World Dev 2007:35:735-51.

4 Wang $\mathrm{H}$, Liddell CA, Coates MM, et al. Global, regional, and national levels of neonatal, infant, and under-5 mortality during 1990-2013: a systematic analysis for the Global Burden of Disease Study 2013. Lancet 2014. May 2 Epub ahead of print.

5 Hoa DP, Nga NT, Malqvist M, et al. Persistent neonatal mortality despite improved under-five survival: a retrospective cohort study in northern Vietnam. Acta Paediatr 2008;97:166-70.

6 Hill K, You D, Inoue M, et al. Child mortality estimation: accelerated progress in reducing global child mortality, 1990-2010. PLoS Med 2012;9:e1001303.

7 Macro International Inc. Trends in demographic and reproductive health indicators in Nepal. Calverton, MD: Macro International Inc., 2007. 
8 Smith SL, Neupane S. Factors in health initiative success: learning from Nepal's newborn survival initiative. Soc Sci Med 2011;72:568-75.

9 Gakidou E, Oza S, Vidal Fuertes C, et al. Improving child survival through environmental and nutritional interventions: the importance of targeting interventions toward the poor. JAMA 2007;298:1876-87.

10 Prost A, Colbourn T, Seward N, et al. Women's groups practising participatory learning and action to improve maternal and newborn health in low-resource settings: a systematic review and meta-analysis. Lancet 2013:381:1736-46.

11 Dalziel K, Segal L. Home visiting programmes for the prevention of child maltreatment: cost-effectiveness of 33 programmes. Arch Dis Child 2012;97:787-98.

12 Chola L, Nkonki L, Kankasa C, et al. Cost of individual peer counselling for the promotion of exclusive breastfeeding in Uganda. Cost Eff Resour Alloc 2011;9:11.

13 Darmstadt GL, Bhutta ZA, Cousens S, et al. Evidence-based, cost-effective interventions: how many newborn babies can we save? Lancet 2005;365:977-88.

14 Hallberg E. The Oats people-studies in population and market development in the Dalbo plain, 1770-1930. University of Gothenburg, 2013.

15 Anderson T, Kohler HP. Education fever and the East Asian fertility puzzle: a case study of low fertility in South Korea. Asian Popul Stud 2013;9:196-215.

16 Vranes HS, Gall V. Secular trends in parental age in Croatia from 1985-2009. Anthropol Anz 2013;70:347-55.
17 Piketty T. Capital in the twenty-first century. Belknap Press, 2014.

18 Al-Bagoury S. Oil in equatorial Guinea: growth without development. Wyno Acad J Soc Sci 2013;1:1-8.

19 Thomsen S, Hoa DT, Malqvist M, et al. Promoting equity to achieve maternal and child health. Reprod Health Matters 2011;19:176-82

20 CSDH. Closing the gap in a generation: health equity through action on the social determinants of health. Final Report of the Commission on Social Determinants of Health. Geneva: World Health Organization, 2008.

21 Malqvist $\mathrm{M}$, Yuan B, Trygg $\mathrm{N}$, et al. Targeted interventions for improved equity in maternal and child health in low- and middle-income settings: a systematic review and meta-analysis. PLOS ONE 2013;8:e66453.

22 Lagarde M, Haines A, Palmer N. Conditional cash transfers for improving uptake of health interventions in low- and middle-income countries: a systematic review. JAMA 2007;298:1900-10.

23 Adams AM, Rabbani $A$, Ahmed $S$, et al. Explaining equity gains in child survival in Bangladesh: scale, speed, and selectivity in health and development. Lancet 2013;382:2027-37.

24 Barham T, Maluccio JA. Eradicating diseases: the effect of conditional cash transfers on vaccination coverage in rural Nicaragua. J Health Econ 2009:28:611-21.

25 McQuestion MJ, Velasquez A. Evaluating program effects on institutional delivery in Peru. Health Policy 2006;77:221-32. 